\title{
Emergence of Metallo- $\beta$ - Lactamase producing Isolates of Pseudomonas aeruogenosa Urinary Tract Infection in Children
}

\author{
Chateen I. Ali Pambuk ${ }^{1 *}$ (D), Sabah M. Salih ${ }^{2}$ and Fatma Mustafa Mohammed ${ }^{1}$ (D) \\ ${ }^{1}$ College of Dentistry, University of Tikrit, Iraq. ${ }^{2}$ College of Pharmacy, University of Kirkuk, Iraq.
}

\begin{abstract}
Infections with Pseudomonas aeruginosa isolates producing Metallo- $\beta$ - Lactamase (MBL) is a serious worldwide infections. It is associated with, higher mortality rates, more severe disease implicated and with a higher incidence of invasive disease than infections with the bacterial isolate of MBLnonproducers. This bacteria disseminated in many countries worldwide, with no reports available about their presence in Iraq. The present study was conducted to investigate the changes and the intensity of antibiotics resistance pattern of pediatric urinary tract infection (UTI) in duration of 2 years as well as reporting the first emergence of Metallo- $\beta$ - Lactamase producing $\boldsymbol{P}$ aerugenos $\boldsymbol{a}$ in Iraq. Standard methods used for isolation and identification of bacteria. Carbapenem- resistance $P$. aeruginosa UTI isolates were tested for the presence of metallo- $\beta$-lactamases productino. This is the first report of the presence of Metallo- $\beta$-Lactamase producing $\boldsymbol{P}$ aerugenosa in Iraq region. The results showed no differences in resistance pattern among Gram positive bacteria isolated. While, their was a dramatic increase of Escherichia coli resistance which showed high sensitivity rate to cefotaxim (72.4\%), recording an increasing rate of resistance by $12 \%$ during 2 years. Klebsiellae pneumoniae resistance profile were increased dramatically during 2 years to trimethoprim and cefotaxim to reach $30 \%$ and $11 \%$ respectively, when compaired with our previous study. Regarding $P$. aeroginosae, there was further increase in resistance toward azithromycin, gentamicin and oxacillin by recording $14 \%, 11.6 \%$ and $11.6 \%$ of resistance rates respectively. The striking results of the present study was to find the resistant bacterial isolates of $P$. aeruginosae toward imipineme. Precisely, 4 (31.8\%) out of 13 UTI isolates was found to be resistant to imipineme. In conclusion their was an different increasing resistance rates of isolates toward antibiotics, also an emergence of new MBL producing $P$. eaurogenosa.
\end{abstract}

Keywards: Metallo- $\beta$ - Lactamase, Pseudomonas eaurogenosa, UTI.

*Correspondence: dr.chatin2@yahoo.com; 009647701808805

(Received: 17 July 2019; accepted: 18 Septemberr 2019)

Citation: Chateen I. Ali Pambuk, Sabah M. Salih and Fatma Mustafa Mohammed, Emergence of Metallo- $\beta$ - Lactamase producin Isolates of Pseudomonas aeruogenosa Urinary Tract Infection in Children, J Pure App/ Microbiol., 2019; 13(4):2309-2316. https:// doi.org/10.22207/JPAM.13.4.46

(C) The Author(s) 2019. Open Access. This article is distributed under the terms of the Creative Commons Attribution 4.0 International License which permits unrestricted use, sharing, distribution, and reproduction in any medium, provided you give appropriate credit to the original author(s) and the source, provide a link to the Creative Commons license, and indicate if changes were made. 


\section{INTRODUCTION}

Urinary tract infection (UTI) defines as significant number $\left(\geq 10^{5}\right)$ Colony Forming Units (CFU) D $\mathrm{ml}$ of pathogenic organism in the urinary system (Schnarr and Smaill,2008). UTI is considered to be the most common nosocomial and community acquired infections, with serious high morbidity and increased economic loss in terms of treatment (Ojo and Anibijuwon, 2010). It causes by invasion of pathogenic microorganism into the urinary tract system (Buonsenso and Gutaldi, 2012) .

The UTI is not uncommon in childhood. About $8 \%$ or more of girls and about $2 \%$ of boys will have a urinary tract infection at some time during childhood. The majority of UTIs occur in the first year of life (Larcombe,1999). Both anatomic and physiologic factors put children at risk of developing UTI. Any anatomic or functional abnormalities of the urinary tract that impede urinary flow can increase the host susceptibility to UTI (Tanagho et al., 2004). Anatomic abnormalities include short urethra in females, urinary obstruction, Vesico ureteral reflux, neurogenic bladder which is the improper storage of urine in bladder and improper emptying of urine from bladder, and uncircumcised in boys. Uncircumcised boys have a great tendency to harbor organisms in the foreskin due to warm, moist and mucosal environment as a result bacteria migrate up to the urethra and colonize in the bladder (Dulczak and Kirk, 2005; Heffner and Gorelick, 2008).

The present study was conducted in order to investigate the changes and the intensity of antibiotics resistance pattern of bacterial UTI describing the susceptibility profiles in Children during two years, according to our previous study (Shahab et al. 2017). Also to characterize the new emergence of carbapenem resistance Pseudomonas aeruginosa .

\section{MATERIALS AND METHODS}

This cross sectional study was carried out from November 2017 to June 2018. Sterile urine samples were collected from children patients, aged 1-10 years, admitted to the Pediatric General Hospital and Kirkuk General Hospital in Kirkuk city, Iraq. Collected urine samples were processed in specific Microbiology laboratory at these Hospitals. Ethics approval in the course of our study was demanded by the Committee of Kirkuk Health Directorate. All the enrolled children patients in the study have signed to give their consents, or were obtained from their parents before collection of urine samples.

\section{Antibiotics sensitivity test using disc diffusion} method

Antibiotic susceptibility patterns for all bacterial isolates were performed using single disc diffusion method, measuring the diameter of inhibition zone of bacterial growth according to the NCCLS Antibiotic susceptibility recommendations (Patel et al., 2014). The antibiotic susceptibility test was conducted on the Muller Hinton agar medium using 10 types of antibiotic discs (Ampicillin, Rifampin, Azithromycin, Novabocin, Chloramphenicol, Cefotaxime, Gentamicin, Amoxycillin-clavulanate, Trimethoprim and Oxacillin) (Bioanalyse). The microbial cultures employed by transferring $5 \mathrm{ml}$ of one pure colony in to nutrient agar medium and incubated at $37^{\circ} \mathrm{C}$ for 24 hours and compared with the standard McFarland solution previously prepared at bacterial concentration of $(0.10 \times 1.5)$ cell / $\mathrm{ml}$. Then $0.1 \mathrm{ml}$ of the above microbial culture were spread in the center of Muller Hinton agar with a sterile glass diffuser and then left to dry at room temperature for 10-15 minutes. The transferred antibiotic discs were emplaned by Sterilize forceps by 5 discs per plate and then incubated at $37^{\circ} \mathrm{C}$ for 24 hours. The diameter of the inhibition zones (including diameter of the disc) was measured and the isolates were divided into 3 categories according to their susceptibility pattern into sensitive, moderatly sensitive and resistant based on the global antibiogram measurements of NCCLS (NCCLS; 2004).

Identification of metallo beta lactamase production by $P$. aeruginosa

The identification of $P$. aeruginosa metallo beta lactamase production isolates was confirmed by employing Epsilometer test (E-test) pursuing Pitout et al. method (2005). Briefly, Thirty confirmed isolates were selected to be tested for their MBL enzyme production by $\mathrm{E}$ test. MBL diagnostic E-test strip consists of a double sided seven dilution range of imipenem (IP) is the basses of identification. MBLE-test was performed according to the manufacturer's instructions ( $A B$ BioMerieux, Solna, Sweden). Stored bacterial 
isolates were subcultured on blood agar plates and were incubated aerobically at $37^{\circ} \mathrm{C}$ for 24 hrs. Suspended pure colonies in a $0.85 \%$ saline were picked from overnight agar plates and were adjusted to a turbidity of $0.5 \mathrm{McF}$.

E-test MBL strips were applied to $\mathrm{MH}$ agar plates inoculated with adjusted suspensions. Seeded $\mathrm{MH}$ agar plates were incubated aerobically for $24 \mathrm{hrs}$ at $37^{\circ} \mathrm{C}$. The minimum inhibitory concentration (MIC) end points were read where the inhibition ellipses intersected the strip. A reduction of imipenem MIC in the presence of EDTA that is greater than or equal to eight-fold (IP/IPI $>8 \mathrm{~mm}$ ) was interpreted as indicating $\mathrm{MBL}$ activity. The presence of a phantom zone or a deformation of the imipenem ellipse was also considered a positive result

\section{RESULTS AND DISCUSSION \\ Distribution of Isolated Bacteria Among Study Groups}

The isolated bacterial distribution of among the study groups, as shown in Table 2, the common isolated bacteria among children with UTI was Escherichia coli which constituted 34.11\% followed by $K$. pneumonia which constitutes $29.41 \%$, followed by $P$. aeruginosa which recorded relatively a high rate of $15.29 \%$. the lowest UTI was Proteus mirabilis (9.41\%) and Staphylococcus epidermidis with Staphylococcus aureus both constituted $5.88 \%$.
Distribution of Antibiotics Sensitivity of Gram Positive Bacteria Isolated From Children with UTI

The vast majority bacteria, among all the bacterial isolates from pediatric UTI, already showed a multidrug-resistance pattern also a different sensitivity to different antibiotics. In this study S. aureus showed a high rate of sensitivity to novabocin $(100 \%)$ while it showed resistant to ampicillin and amoxicillin-clavulanate with a high recorded rate of $100 \%$ (Fig. 1). S. epidermidis shows high rate of sensitivity to azithromycin and novabocin (100\%) while it was found to be completely resistant to ampicillin, oxacillin and trimethoprim (100\%) (Fig. 1) .

It is worth mentioning, in antibiotic era, that the right selection of antibiotic for successful treatment depends on 2 important factors the spectrum of the antibiotic used and the patterns of susceptibility for the uropathogens, its effectiveness for this indication, its collateral effects and coast (Naber et al., 2011). In current study S. aureus showed high sensitivity to Novabiocin $100 \%$ and it was resistant to ampicillin and tetracyclin with recorded ratio of $100 \%$. S. epidermidis showed high sensitivity to novabiocin, azithromycin and genatmicin with rate of $100 \%$, while it was $100 \%$ resistant to each of ampicillin, oxacillin and trimethoprim and this is the same resistance profile found before 2 years (Shahab et al. 2017).

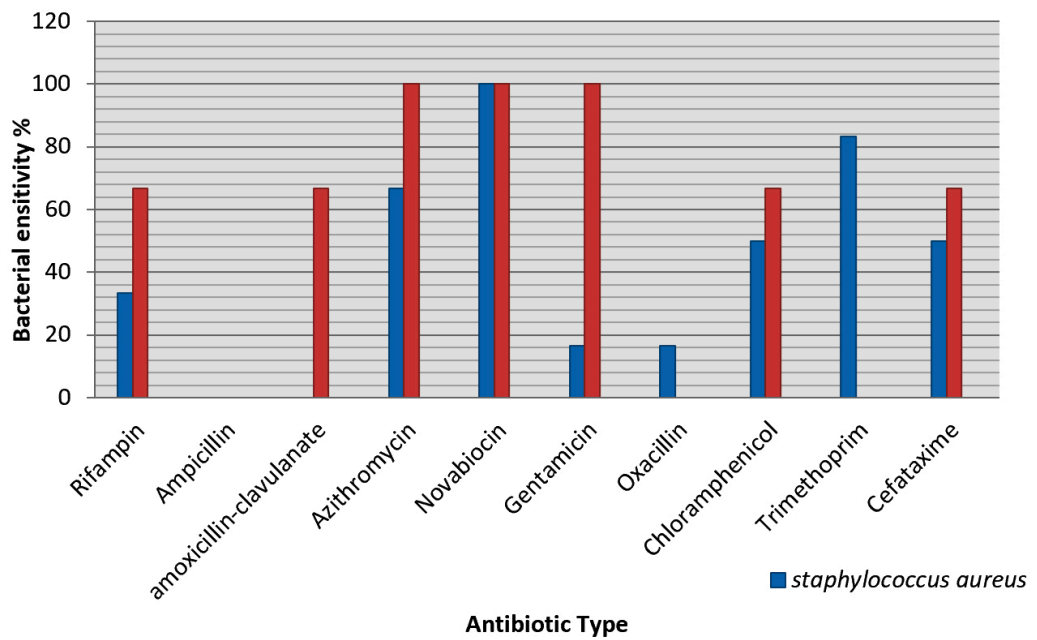

Fig. 1. Distribution of Antibiotics sensitivity of Gram Positive Bacteria Isolated from Children with UTI. 
A study reported that novabiocin is the most effective antibiotic against $S$. aureus and $S$. epidermidis. As can be seen from results, high resistance of bacterial isolates to ampicillin, the reason is due to a production of the enzyme $\beta$-Lactamase that analyst for the $\beta$-Lactam ring in the antibiotic and is transformed into composite ineffective and the resistance is due to the change in the permeability of cell membranes of bacteria. The bacteria shows different mechanisms of antibiotic resistance such qualities autopsy for example, the components of plasma membrane role in receiving antibiotics and transfer from outside to inside the cell and access to objective, which affect on it, the absence of such as a result of obtaining genetic mutation leads to resistant bacteria to antibiotic. Plasmids have a pivotal role in the transfer of resistance because the presence of genes that code for them when it moves to does not contain bacteria become resistant after it was sensitive for those antibiotics this is achieved either through transformation, conjugation, transduction and other mechanisms (Mahdi,2009).

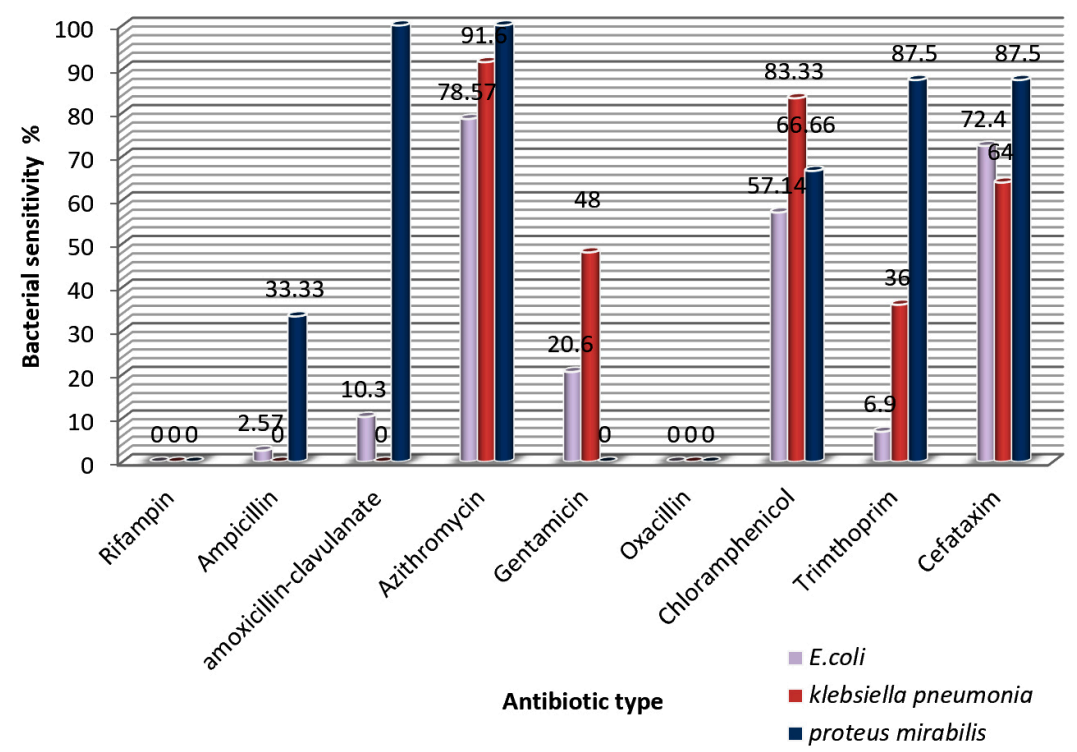

Fig. 2. Distribution of Antibiotics Sensitivity of Gram Negative Bacteria Isolated from children with UTI.

Table 1. Antibiotic discs used in the current study and the global antibiogram activity

\begin{tabular}{|c|c|c|c|c|}
\hline \multirow[t]{2}{*}{ Antibiotics } & \multirow[t]{2}{*}{$\begin{array}{l}\text { Potency } \\
\mu g / \text { disc }\end{array}$} & \multicolumn{3}{|c|}{$\begin{array}{l}\text { Diameter of inhibition } \\
\text { zone }(\mathrm{mm})\end{array}$} \\
\hline & & Resistant & Intermediate & Sensitive \\
\hline Ampicillin & 25 & $\leq 13$ & $14-16$ & $\geq 17$ \\
\hline Rifampin & 5 & $\leq 16$ & $14-17$ & $\geq 20$ \\
\hline Azithromycin & 15 & $\leq 20$ & & $\geq 21$ \\
\hline Novabocin & 30 & $\leq 17$ & $18-21$ & $\geq 22$ \\
\hline Chloramphenicol & 10 & $<12$ & $12-17$ & $>18$ \\
\hline Cefotaxime & 30 & $\leq 14$ & $15-18$ & $\geq 19$ \\
\hline Gentamicin & 10 & $\leq 12$ & $13-14$ & $\geq 15$ \\
\hline $\begin{array}{l}\text { Amoxycillin- } \\
\text { clavulanate }\end{array}$ & 10 & $\leq 12$ & $15-18$ & $\geq 19$ \\
\hline Trimethoprim & 5 & $\leq 10$ & $11-15$ & $\geq 16$ \\
\hline Oxacillin & 5 & $\leq 10$ & $11-12$ & $\geq 13$ \\
\hline
\end{tabular}


Distribution of Antibiotics Sensitivity of Gram Negative Bacteria Isolated From Children with UTI

The vast majority of uropathogenes, among the all bacteria that were isolated from urine, already showed a multidrug-resistance pattern spread deferentially among the bacterial isolates. In which $E$. coli showed high rate of resistance (100\%) to oxacillin and rifampin with also high resistance toward trimethoprim reached $6.9 \%$, while were sensitive (72.4\%) to cefataxim with also low rates of sensitivity toward amoxicillin-clavulanate and gentamycin recorded $10.3 \%, 20.6 \%$ respectivally (Fig. 2 ). $K$. pneumoniae shows high rate of sensitivity (91.6\%) to azithromycin and it is resistant to ampicillin, amoxicillin-clavulanate, rifampin, oxacillin (100\%), with a low sensitivity rates toward gentamycin, trimethoprim and cefotaxim reached 48\%, 36\% and $64 \%$ respectively. $P$. mirabilis shows high sensitivity rate to cefotaxim and trimethoprim (87.5\%) for both and $100 \%$ for azithromycin. The bacteria showed resistant to rifampin, ampicillin, oxacillin and gentamicin (100\%) (Fig. 2).

There is generally a positive correlation between antibiotic consumption and incidence of resistance to antibiotic used either for prophylaxis or therapy in infections (Mahdi, 2009). E. coli shows high sensitivity rate to cefotaxim (72.4\%), recording an increasing rate of resistance by
12\% during 2 years (Shahab et al. 2018). also it has $100 \%$ resistant to each of oxacillin, rifampin and trimethoprim. K. pneumoniae shows high sensitivity rate $(91.6 \%)$ to azithromycin and it has $100 \%$ resistant to ampicillin, tetracycline, rifampin and oxacillin, while the resistance profile were increased dramatically during 2 years to trimethoprim and cefotaxim to reach $30 \%$ and $11 \%$ respectively, when compared with our previous study (Shahab NW, et.al 2017). Proteus mirabilis shows high sensitivity rate to cefotaxim, tetracyclin. and azithromycin (100\%) and it has $100 \%$ resistant to gentamicin, rifampin and oxacillin. Regarding trimethoprim and cefotaxim

Table 2. Percentile values of bacterial distribution among pediatric UTI

\begin{tabular}{lcc}
\hline Isolated Bacteria & \multicolumn{2}{c}{$\begin{array}{c}\text { Positive Bacterial } \\
\text { UTI Cases } \\
\text { Children with UTI }\end{array}$} \\
\cline { 2 - 3 } & NO & $\%$ \\
\hline E.coli & 29 & 34.11 \\
Klebsiella pneumonia & 25 & 29.41 \\
Pseudomonas aeruginosae & 13 & 15.29 \\
Proteus mirabilis & 8 & 9.41 \\
Staphylococcus aureus & 5 & 5.88 \\
Staphylococcus epidermidis & 5 & 5.88 \\
Total & 85 & $100 \%$ \\
\hline
\end{tabular}

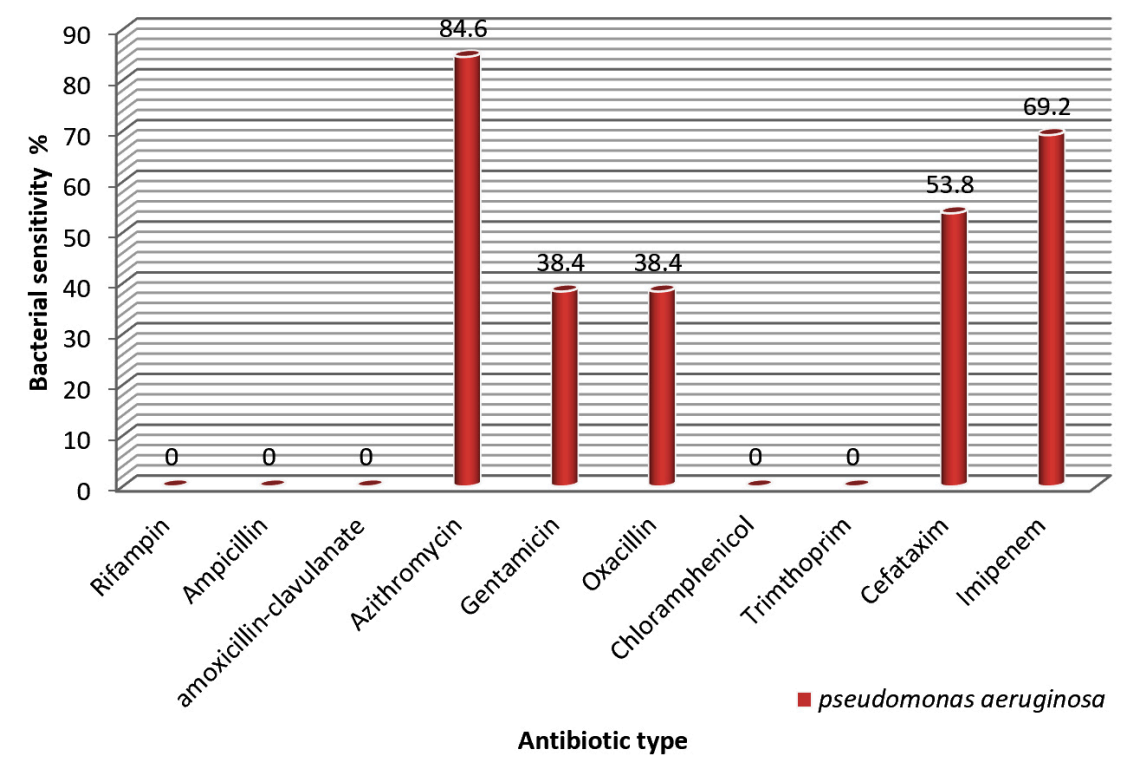

Fig. 3. Sensitivity pattern of Pseudomonas aeruginosa toward different antibiotics tested. 
the resistance pattern increased by $12.5 \%$ for both antibiotic. The resistance pattern is increasing gradually in the city of Kirkuk since we recorded an effective similar antibiotics against bacterial cause of UTI 10 years ago (Issa et al. 2007)

Regarding $P$. aeroginosae, the bacteria showed high sensitivity rate to azithromycin $(84.6 \%)$ ). Furthermore, the sensitivity rates of the bacterial isolates toward gentamicin, oxacillin, cefotaxim recorded a values of $38.4 \%, 38.4 \%$ and $53.8 \%$ respectively. When compared to our previous study there is also further increase in resistance toward azithromycin, gentamicin and oxacillin by recording $14 \%, 11.6 \%$ and $11.6 \%$ of resistance rates respectively.

The striking results of the present study was to find the resistant bacterial isolates of $P$. aeroginosae toward imipineme. Precisely, 4 (31.8\%) out of $13 \mathrm{UTI}$ isolates was found to be resistant to imipineme. The sensitivity rate was found to be $69.2 \%$ (Fig. 3).

$P$. aeruginosa showed a high sensitivity rate to azithromycin (84\%) and the resistance rate was to ampicillin (100\%). The current study is in agreement with Kandela (Kandela,2011) who reports that multi resistance to antibiotics ranging between antibiotics, and all $K$. pneumoniae UTI isolates were resistant $100 \%$ to ampicillin, amoxicillin-clavulanate. (Amin et al., 2009) in his study found that Gram negative bacilli were responsible for UTI infections, the most common isolated bacteria from urinary infections were $E$. coli and the most effective antimicrobial agents were azithromycin against Gram negative bacilli.

The highly sensitivity of all bacterial isolates to azithromycin lead to consider that this drug is the best for treatment of UTI, the sensitivity of isolated gram-negative bacteria E. coli, Klebsiella species, $P$. mirabilis and $P$. aeruginosa was most prominent to amino-glycoside (gentamicin) (Lazarevic et al., 1998). Whereas ampicillin which has a significant role in the treatment of UTI has showed increased resistance rates among $E$. coli and Klebsiella species, Klebsiella species have natural resistance against ampicillin. $P$. mirbilis species are often sensitive to aminoglycoside and penicillin .

The use of ampicillin as single agents in the treatment of UTI may not be of great value as they have high resistance rates when compared to amikacin and gentamicin that have a great value as an empirical treatment of UTI in children above one years.

Carbepenem-resistant strains of $P$. aeruginosae have been reported in more than 50 country with different proportions and geographical distribution of the bacterial prevalence, with many CRPA strains have been identified and their dissemination is increasing gradually (Hong DJ et al. 2015) .

The detection of Metallo- $\beta$ - Lactamase producing $P$. eaurogenosa was done on phenotypic basis. Further genotypic based studies is necessary to disclose the exact type of this resistant bacteria, by detecting such as imipenemase (IMP) producing, Verona integron-encoded (VIM), Sao Paulo metallo-beta-lactamase (IMP), German imipenemase (GIM), Seoul imipenemase (SIM) and NDM encoding genes by performing polymerase chain reaction technique.

The recommendation disclosed to health care personnel is to promote their care and activate health promotion teams, to strictly ensure that the standard measures for infection prevention and control (IPC) and all the important policies regardingly are precisely implemented; highly regulated antibiotic stewardship is done ; integrated patient education activities and counseling is ongoing; and ensure the availability of a good quality microbiology diagnosis approach. All the above precautions is needed to be fulfilled in every single medical facility across the country.

The ability of Metallo- $\beta$ - Lactamase producing $P$. eaurogenosa to spread and detected in community based pediatric UTI, implies the possibility for numerous new $\mathrm{MBL}$ cases to be detected in the near future especially the nosocomial dissemination. If we look at the nature of spreading, a rapid emergence of new MBL cases might be expected in all medical settings in Iraq. Medical center-based study in each province and medical sector is urgently in need.

\section{CONCLUSION}

E. coli demonstrated an increasing rate of resistance to ceftataxim during 2 years. The same increase in resistance pattern thing can be concluded about $K$. pneumoniae and Proteus toward different antibiotics. Regarding $P$. aeroginosae, there was further increase in 
resistance toward azithromycin, gentamicin and oxacillin. The striking results of the present study was to find the resistant bacterial isolates of $P$. aeroginosae toward imipineme. New emergence of Metallo- $\beta$-Lactamase producing $P$. eaurogenosa in Iraq.

\section{ACKNOWLEDGEMENT}

Authors would like to acknowledge Kirkuk health directorate that allowed us to conduct this research in Kirkuk hospitals, Kirkuk pediatric hospital and Kirkuk General Hospital. Apart from that, other private clinics and laboratories assisted our work. Our thanks and appreciation goes to the staff, laboratory worker at pediatric Hospitals, private clinics and laboratories for their help during the sampling.

\section{CONFLICTS OF INTEREST}

The authors declare that there is no conflict of interest.

\section{FUNDING}

None.

\section{AUTHORS' CONTRIBUTION}

All authors listed have made a substantial, direct and intellectual contribution to the work, and approved it for publication.

\section{DATA AVAILABILITY}

All datasets generated or analyzed during this study are included in the manuscript and/or the Supplementary Files.

\section{ETHICS STATEMENT}

The study is approved by the research ethics board of Kirkuk health directory No. 18255. Also approved by the ethics board by the University of Tikrit Written informal consent was obtained from patients (or substituted decisionmakers).

\section{REFERENCES}

1. Schnarr, J., Smaill, F. Asymptomatic bacteriuria and symptomatic urinary tract infections. Eur J Clin Invest; 2008; 38(2): 50-57. https://doi.org/10.1111/j.13652362.2008.02009.x

2. Ojo, O.O., and Anibijuwon, I.I. Urinary tract infection among female students residing in the campus of the University of Ado Ekiti, Nigeria. Afr. J. Microbiol. Res.,
2010; 4(12): 1195-1198.

3. Buonsenso, D., Cataldi, L. Urinary tract infections in children: a review. Minerva Pediatr, 2012; 64: 145-57.

4. Larcombe, J. Urinary tract infection inchildren. BMJ, 1999; 31: 173-5. https://doi. org/10.1111/j.1469-0691.1999.tb00806.x

5. Tanagho, Emil A., Mcaninch, Jack, W. Smith's General Urology. United States of America: McGrawHill companies Inc. Bacterial Infections of the genitourinary, 2004.

6. Dulczak, S., Kirk. Overview of the evaluation, diagnosis, and Management of urinary tract infections in infants and children, Urologicnursing, 2005; Available:http:// www.medscape.com/viewarticle/507162.

7. Heffner, V., Gorelick, M. Pediatric Urinary Tract Infection. Clin. Ped. Emerg. Med., 2008; 9: 233-237. https://doi.org/10.1016/j.cpem.2008.09.009

8. Manges AR, Natarajan P, Solberg OD, Dietrich PS, Riley LW. The changing prevalence of drug-resistant Escherichia coli clonal groups in a community: evidence for community outbreaks of urinary tract infections. Epidemiol. Infect., 2006; 2: 425-31. https:// doi.org/10.1017/S0950268805005005

9. Kahan NR, Chinitz DP, Waitman DA, Dushnitzky D, Kahan E, Shapiro M. Empiric treatment of uncomplicated urinary tract infection with fluoroquinolones in older women in Israel: another lost treatment option? Ann Pharmacother., 2006; 12: 2223-7. https://doi. org/10.1345/aph.1H396

10. Gupta K, Scholes D, Stamm WE. Increasing prevalence of antimicrobial resistance among uropathogens causing acute uncomplicated cystitis in women. JAMA, 1999; 281: 736-8. https://doi.org/10.1001/jama.281.8.736

11. Pitout JD, DB Gregson, L Poirel, J McClure, P. Le and DL Church. Detection of Pseudomonas aeruginosa producing metallo-B-lactamases in a large centralized laboratory. J. Clin. Microbiol., 2005; 43(7): 3129-3135. https://doi.org/10.1128/JCM.43.7.3129-3135.2005

12. Morales E., F. Cots, M. Sala, M. Comas, F. Belvis, M. Riu, M. Salvado, S. Grau, J.P. Horcajada, M.M. Montero and others. Hospital costs of nosocomial multi-drug resistant Pseudomonas aeruginosa acquisition. BMC Health Serv. Res., 2012; 12: 122. https://doi. org/10.1186/1472-6963-12-122

13. Shahab NW, Chatin IA Pambuk, Sabah MS. Isolation and Identification of bacteria causing urinary tract infections in children in Kirkuk city. Tikrit Journal of Pure Science, 2017 ; 22(2): 8-12

14. Patel J.B., F.R. Cockerill, J. Alder, P.A. Bradford, G.M. Eliopoulos, D.J. Hardy, J.A. Hindler, S.G. Jenkins, J.S. Lewis, L.A. Miller and others. Performance standards for antimicrobial susceptibility testing; twenty fourth informational supplement. M100-S24. CLSI, 2014; 34(1): 1-219.

15. Alexander, S.K. and Street, D. Microbiology: photographic Atlas for laboratory.21thed.Jones and Bartlett publishers, Boslon. Inc. New York, 2001.

16. Naber, KG., Wullt, B., Wagenlehner, F.M. Antibiotic treatment of uncomplicated urinary tract infection premenopausal women. Inter. J. antimicrob agents, 2011; 285: 21-35. https://doi.org/10.1016/j. ijantimicag.2011.09.003 
17. Issa SB, SA Anwar, CE Ali. Study of urinary tract infection among pregnant women in Kirkuk. Medical Journal of Tikrit, 2007; 13(2): 39-43.

18. Kandela, NJ. Detection of extended spectrum $\beta-$ lactamase (ESBL) and klobocin production from Klebsiella pneumoniae local isolates from urinary tract infections. J. APS, 2011; 11(1): 21-42.

19. Amin. M, Mehdinejad, M, Pourdangchi Z. Study of bacteria isolated from urinary tract infections and determination of their susceptibility to antibiotics. Jundishapur J. Microbiol., 2009; 2(3): 118-123. tract. p 203-227.

20. Lazarevic, G, Petreska, D, Pavlovic, S. Antibiotic sensitivity of bacteria isolated from the urine of children with urinary tract infections from 1986 to 1995. Srp. Arh. Celok. Lek., 1998; 126(11-12): 423-9.

21. Hong DJ, Bae IK, Jang IH, Jeong $\mathrm{SH}$, Kang HK, Lee
K. Epidemiology and Characteristics of Metallo$\beta$-Lactamase-Producing Pseudomonas aeruginosa. Infect. Chemother., 2015; 47(2): 81-97. https://doi. org/10.3947/ic.2015.47.2.81

22. Mendes RE, Bell JM, Turnidge JD, Castanheira M, Jones RN. Emergence and widespread dissemination of OXA-23, -24/40 and -58 carbapenemases among Acinetobacter spp. in Asia-Pacific nations: report from the SENTRY Surveillance Program. J. Antimicrob. Chemother., 2009; 63: 55-59. https:// doi.org/10.1093/jac/dkn434

23. Voor In't Holt AF, Severin JA, Lesaffre EM, Vos MC. A systematic review and meta-analyses show that carbapenem use and medical devices are the leading risk factors for carbapenem-resistant Pseudomonas aeruginosa. Antimicrob Agents Chemother., 2014; 58: 2626-2637. https://doi.org/10.1128/AAC.01758-13 